\title{
ASOCIACIÓN ENTRE TUMOR DE CÉLULAS GERMINALES Y MALIGNIDADES HEMATOLÓGICAS
}

J avier Orlando Pacheco G. M D*, Virginia A bello P.M D**, Olga Paola O maña M D***

\section{Resumen}

Los tumores de células germinales representan el $2 \%$ de las malignidades humanas siendo más común en hombres entre los 15 y 35 años. Cerca de 2 a $5 \%$ ocurren extragonadales. Garnik informó la asociación entre malignidades hematológicas y TCG en 1983, desde entonces varios casos han sido reportados; la mayoría se presentan con TCG no seminomatosos y neoplasias hematológicas de índole megacariocítica. Tienen mal pronóstico y resistencia a los tratamientos, la mayoría mueren durante el manejo inicial al diagnóstico y no existen protocolos óptimos para su manejo. Reportamos un caso de leucemia de células peludas (LCP) tratada con rituximab con un TCG de tipo seminoma clásico manejado con protocolo (PEB) platino, etoposido y bleomicina, logrando una adecuada respuesta clínica.

Palabras clave: tumor de células germinales, leucemia de células peludas, seminoma, leucemia, megacariocitos.

Abreviaturas: TCG, tumor de células germinales: LCP, leucemia de células peludas.

\section{GERM CELL TUMORS ASSOCIATED WITH HEMATOLOGIC MALIGNANCIES}

\section{Abstract}

Germ cell tumors account for $2 \%$ of malignancies in humans, predominantly affecting men aged 15 to 35 years. Almost 2 to $5 \%$ occur at extragonadal sites. Garnik reported the association between hematologic malignancies and GCTs in 1983. Several cases have been reported since then; most of them present as nonseminomatous GCTs associated with magakaryocytic hematologic malignancies. They are resistant to treatment and prognosis is poor, most patients die within the initial phase of treatment after diagnosis. Optimal management protocols are not available. We report one case of hairy cell leukemia (HCL) treated with rituximab, associated to a classic seminoma type GCT managed with a bleomycin, etoposide, platinum (BEP) combination regimen, achieving an adequate clinical response.

Key words: germ cell tumor, hairy cell leukemia, seminoma, leukemia, megakaryocytes

Fecha recibido: septiembre 16 de 2014 - Fecha aceptado: noviembre 27 de 2014

* Internista, hematooncólogo, Hospital de San José. Instructor Asistente Fundación Universitaria de Ciencias de la Salud. Bogotá DC, Colombia.
** Internista, hematóloga, Hospital de San José. Instructor Asistente, Fundación Universitaria de Ciencias de la Salud. Bogotá DC, Colombia.

*** Residente III de Medicina Interna, Fundación Universitaria de Ciencias de la Salud. Bogotá DC, Colombia. 


\section{Introducción}

L as neoplasias hematológicas asociadas con TCG extragonadales representan uno de los más interesantes aspectos clínicos con elementos distintivos entre los tumores germinales de los hombres. ${ }^{1}$ Esta asociación fue descrita en 1985 tras el reporte de al gunos casos, donde la histología no seminomatosa es la más frecuente; de ellos el teratocarcinoma y los tumores del seno endodérmico son los más reportados. ${ }^{1,2}$ U na serie con 16 pacientes evidenció un intervalo de seis meses (rango de 0 a 122 meses) entre el diagnóstico de la masa mediastinal originada por el tumor germinal hasta la aparición del desorden hematológico. Cerca de un tercio de los pacientes se presentan con ambas lesiones en forma simultanea ${ }^{3}$, la alteración hematológica más frecuente es la dependiente del linaje megacariocítico, dando lugar a una leucemia megacarioblástica aguda con mielodisplasia anormal de los megacariocitos y trombocitosis esencial o idiopática. 0 tros diagnósticos hematológicos incluyen leucemia linfoblástica, mieloblástica aguda y en raros casos histiositosis maligna o mastocitosis sistémica. ${ }^{4,5}$

Las leucemias asociadas con TCG no tienen anormalidades genéticas específicas; sin embargo, el marcador cromosómico típico anormal del cáncer testicular que es el isocromosoma i(12p) se ha identificado en al gunas células leucémicas. O tros hallazgos raros de los blastos incluyen cariotipo XXY o trisomía 21, que pueden ser documentados en los TCG y los síndromes de $\mathrm{K}$ linefelter o D own. ${ }^{6,7 T} T$ ambién se han visto otros desórdenes hematológicos entre las leucemias secundarias con el uso de al quilantes en TCG. ${ }^{8} \mathrm{EI}$ curso clínico de las neoplasias hematológicas en pacientes con TCG tiende a ser muy agresivo, con dificultad responden a la terapia y no logran remisiones. A quellos con trombocitosis aislada o con desórdenes plaquetarios tienen un pronóstico favorable ${ }^{4,5}$

\section{Presentación del caso}

Paciente de 46 años con cuadro clínico de dos años de evolución consistente en aparición de masa en región supraclavicular izquierda de crecimiento lento y progresivo, acelerado en los últimos meses con limitación para los movimientos del cuello, dolor lumbar y parestesias de miembros inferiores. En su evaluación inicial se solicitó biopsia de la masa descrita con estudio de inmunohistoquímica reportando tumor germinal de tipo seminoma clásico. Se ordenaron estudios de imágenes tomográficas en cueIlo con hallazgo de conglomerados ganglionares que comprometen los niveles cervicales izquierdos V y V II, en la región lumbar hay lesión ósea a nivel de $L 2$ de aspecto metastásico y la ecografía testicular descarta compromiso tumoral.

La resonancia magnética de columna lumbo sacra muestra lesión metastásica en el cuerpo vertebral de L 2 con compromiso de los pedículos y masa intrarraquídea extradural, produciendo compresión radicular. Dados estos síntomas se decide dar inicio a la prefase de quimioterapia con dexametasona $16 \mathrm{mg}$ IV cada 12 horas y radioterapia, logrando control de los síntomas neurológicos.

A I inicio de la terapia se observó la presencia de leucopenia por lo que se estudió la médula ósea con biopsia que mostró celularidad variable entre 5 y $20 \%$, sin compromiso neoplásico tumoral; teniendo en cuenta que se había documentado una neopl asia de células germinales y persistencia de al teraciones en los recuentos hematológicos, se llevó a nuevo estudio de médula que evidenció celularidad del $60 \%$ e infiltración por células linfoides con fenotipo y estudio inmunológico por citometria de flujo que mostró CD 11C, B cl-2, CD 20 y débil positividad para ciclina $D 1$. Los resultados de CD 3, CD5, CD23 y OCT3-4 fueron negativos. El mielograma evidenció un compromiso infiltrativo de linfocitos con núcleos homogéneos en el 52,3\%, morfología compatible con células peludas.

La descripción detallada del TAC de cuello reportó tres masas sólidas desde el espacio cervical posterior izquierdo a lo largo del hemicuello hasta la entrada torácica, una de $97 \times 50 \mathrm{~mm}$ que se extiende al mediastino anterior, la segunda más inferior de $47 \times 65$ mm y una más pequeña de $27 \times 23 \mathrm{~mm}$. La tomografía de tórax mostró extensos conglomerados mediastina-

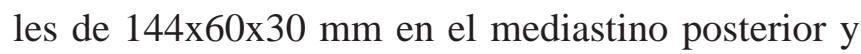
masa perivascular de $77 \times 60 \mathrm{~mm}$ y otra paravertebral izquierda de 102x47 mm, lesiones no documentadas en imágenes previas. 
La tomografía de abdomen con contraste reportó un conglomerado retroperitoneal de $74 \times 32 \mathrm{~mm}$, que aumentó de tamaño con respecto al estudio anterior realizado tres meses previos al ingreso. El ecocardiograma y la filtración glomerular fueron normales y el perfil viral fue negativo. El paciente no refirió antecedentes de importancia, excepto pérdida de peso de cerca de $5 \mathrm{k}$ desde el inicio del cuadro clínico.

El estado general fue regular, con dificultad respiratoria leve dada por taquipnea con gran masa blanda multinodular de $15 \times 10 \mathrm{cms}$ en el lado izquierdo del cuello, con evidente desplazamiento de la vía aérea a la derecha e ingurgitación venosa izquierda (Figura 1). En el abdomen se identificó hepatomegalia de 2 $\mathrm{cm}$ bajo el reborde costal derecho, sin evidencia de esplenomegalia.

Durante su evolución presentó deterioro clínico por el efecto mecánico de la masa en cuello. Ingresó para nuevos estudios cuya biopsia cervical mostró tejido infiltrado por una lesión tumoral constituida por una población de células monomorfas, grandes, redondas o poliédricas, con membrana citoplasmática nítida y citoplasma amplio con núcleos hipercromáticos y nucleolos prominentes, separados por septos fibrosos con abundante presencia de infiltrado inflamatorio mononuclear asociado con extensa necrosis

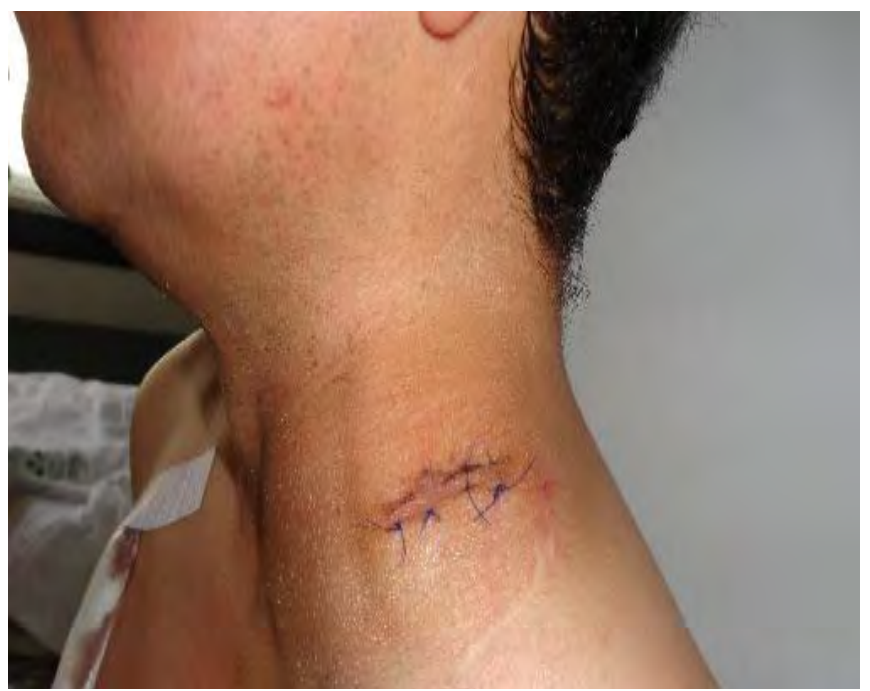

Figura I. Lesión en región cervical al ingreso. Se observa gran masa que compromete región lateral izquierda del cuello que se extiende hacia la región medial, ejerciendo compresión extrínseca a la vía aérea. tumoral. Se realizó estudio de inmunohistoquímica que fue positivo para vimentina, OCT 3-4 CD 117 y PLAP. Se encontró positividad para CD 45 en la población acompañante y fue negativo para CEA, EM A, fosfatasa alcal ina, alfafetoproteina y B-HCG reconfirmándose el diagnóstico de seminoma clásico estadio final IIIC (M Ib) S0 y leucemia de células peludas, cariotipo $46 \mathrm{XY}$.

Para efecto terapéutico se decidió iniciar el protocolo con quimioterapia PEB y rituximab concomitantes, con soporte de factores estimulantes de colonias granulocíticas (pegfilgastrim) por neutropenia severa preexistente y la comorbilidad propia de dos neoplasias, una de ellas con componente hematológico.

En el primer ciclo de tratamiento con quimioterapia presentó una neutropenia febril con aislamiento microbiológico de Pseudomona aeruginosa multisensible, realizándose cubrimiento con piperacilina tazobactam (4,5 g IV cada 6 horas x 10 días), como única complicación resuelta de forma positiva para el paciente, permitiéndose la recuperación hematológica del recuento de neutrófilos y la continuidad del protocolo de quimioterapia, completando cuatro ciclos de rituximab para la LCP y cuatro de PEB para el seminoma, acompañados del pegfilgastrim, lográndose mantener la dosis y frecuencia planeada que llevaron a una remisión hematológica, clínica y paraclínica (Figura 2).

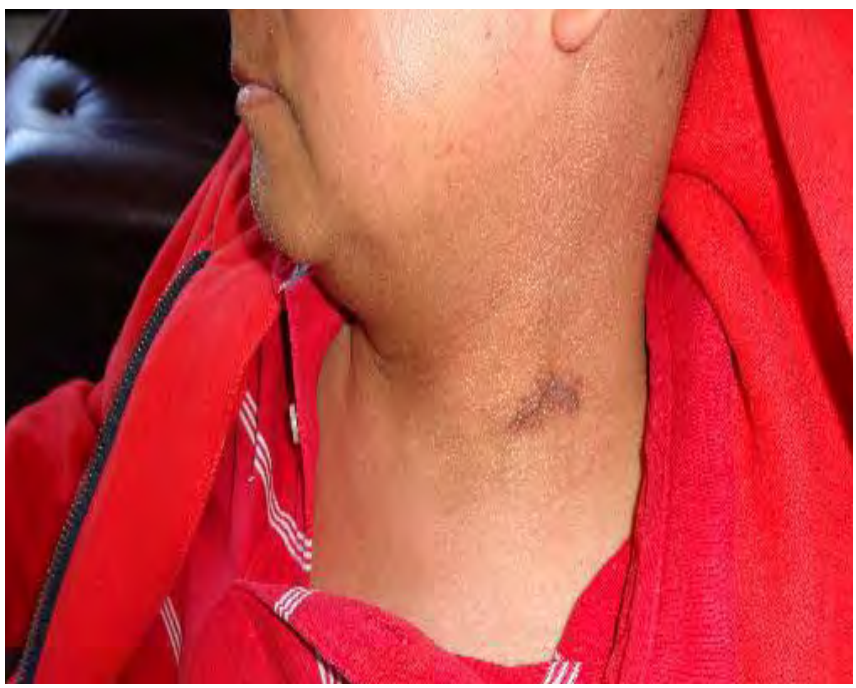

Figura 2. Lesión cervical posterior a tercer ciclo de quimioterapia; se observa franca disminución de la lesión cervical descrita. 


\section{Disc usión}

Este es un nuevo caso de los reportados en la literatura (cerca de 70), correspondiente a un adulto joven con TCG de tipo seminoma asociado con LCP, el primero descrito según nuestro conocimiento, pues las malignidades hematológicas más frecuentes son de linaje megacariocítico M 7, los síndromes mielodisplásicos megacariocíticos y al gunos casos descritos de leucemia linfoblástica aguda, pero hasta ahora ninguna que se refiera a las células peludas. El análisis citogenético de la médula ósea no mostró anormalidades, pero la más frecuente es el isocromosoma i(12p) en un rango del 35 a $38 \%$, según los datos de la literatura. ${ }^{9,10} \mathrm{La}$ presentación del TCG y el desorden hematológico de este paciente fue sincrónico, como ocurre en 10 a $30 \%$ de dos series ${ }^{2}$, donde en su mayoría el intervalo de los dos diagnósticos se describe con un tiempo mediano de seis meses. ${ }^{2}$

El curso clínico es muy agresivo, algunos pacientes mueren antes de iniciar otro tratamiento sin respuesta a la terapia antileucémica o bien hay remisiones muy cortas. El trasplante alogénico puede ser la única estrategia curativa, observado en dos casos reportados ${ }^{10}$. Sin embargo, el subgrupo de pacientes con desórdenes plaquetarios parece tener un mejor pronóstico y en nuestro caso con LCP donde mostró una respuesta favorable con remisión hematológica completa.

L a mediana de supervivencia es de cinco meses con un rango de 0 a 16 meses $^{11,12}$, mientras que al rededor de $50 \%$ con TCG no seminomatoso tienen una vida larga tratados con qui mioterapia. Ninguno de los pacientes reportados con adición de una malignidad hematológica está vivo a los cinco años después del diagnóstico. ${ }^{11}$ El paciente tratado en este reporte lleva un mes de supervivencia, siendo el primer caso de registro de un seminoma clásico de TCG, ya que la mayoría no son seminomatosos mediastinales.

L os TCG no seminomatosos tienen la capacidad de diferenciación totipotencial, que va del carcinoma embrionario pluripotencial a tipos celulares somáticos 0 extraembrionarios (teratomas). En raras ocasiones los teratomas sufren una transformación maligna a componentes somáticos indistinguibles de malignidades primarias como sarcoma o adenocarcinoma, en consecuencia las malignidades hematológicas pueden representar la transformación maligna de tejido hematopoyético dentro de los TCG extragonadales. Soporta esta hipótesis el hecho de que el marcador citogenético especifico del TCG i(12p) fue encontrado en la médula ósea de varios casos reportados. ${ }^{9,12}$

L a incidencia de leucemias en los enfermos con TCG mediastinal no seminomatoso se estima del $5,9 \%{ }^{3}$ y los datos de tratamiento son limitados. En once centros europeos y americanos ${ }^{3}$ los pacientes recibieron tratamientos basados en platinos. Nuestro caso recibió protocolo PEB sin complicaciones y rituximab logrando remisión. Sin embargo, se requieren mayores estudios e investigación de series involucradas en esta asociación que permitan establecer el mecanismo patogénico y el desarrollo de estrategias terapéuticas más efectivas.

\section{Referencias}

1. Hartmann JT, Nichols CR, Droz JP, et al. Hematologic disorders associated with primary mediastinal nonseminomatous germ cell tumors. J Natl Cancer Inst. 2000; 92:54-61.

2. Nichols CR, Roth BJ, Heerema N, Griep J, Tricot G. Hematologic neoplasia associated with primary mediastinal germ-cell tumors. N Engl J Med. 1990; 322:1425-9

3. Ikdahl T, Josefsen D, Jakobsen E, Delabie J, Fosså SD. Concurrent mediastinal germ-cell tumour and haematological malignancy: case report and short review of literature. Acta Oncol. 2008; 47:466-9.

4. Reynoso E, Yau J, Shepherd F, Bailey D, Evans, Baker M. Acute leukemia and mediastinal teratocarcinoma. Proc Am Sue Clin Oncol. 1986; 5: 97.

5. DeMent SH, Eggleston JC, Spivak JL. Association between mediastinal germ cell tumors and hematologic malignancies. Report of two cases and review of the literature. Am J Surg Pathol. 1985; 9: 23-30.

6. Dulmet EM, Macchiarini P, Suc B, Verley JM. Germ cell tumors of the mediastinum. A 30-year experience. Cancer. 1993; 72:1894-901.

7. Garnick MB, Griffin JD. Idiopathic thrombocytopenia in association with extragonadal germ cell cancer. Ann Intern Med. 1983; 98: 926-7.

8. Fanti D, Giudice CR, Truchet C, Damia H, Tejerizo JC, Brugnone R. Tumores Extragonadales. Rev Arg de Urología y Nefrología. 1988; 54(1): 43-4.

9. Heimdal K, Evensen SA, Fosså SD, et al. Karyotyping of a hematologic neoplasia developing shortly after treatment for cerebral extragonadal germ cell tumor. Cancer Genet Cytogenet. 1991; 57: 41-6.

10. Dexeus FH, Logothetis CJ, Chong C, Sella A, Ogden S. Genetic abnormalities in men with germ cell tumors. J Urol. 1988; 140: 80-4.

11. Chaganti RS, Ladanyi M, Samaniego F, Offit K, Reuter VE, Jhanwar SC, et al. Leukemic differentiation of a mediastinal germ cell tumor. Genes Chromosomes Cancer. 1989; 1:83-7

12. Ladanyi M, Samaniego F, Reuter VE, et al. Cytogenetic and immunohistochemical evidence for the germ cell origin of a subset of acute leukemias associated with mediastinal germ cell tumors. J Natl Cancer Inst. 1990; 82: 221-7. 